\title{
Recontextualización multimodal de las acciones y motivaciones del movimiento estudiantil chileno en un reportaje de televisión*
}

\author{
Camila Cárdenas Neira** \\ Carolina Pérez Arredondo***
}

\begin{abstract}
Resumen
En septiembre de 2014, un reportaje de Canal 13 mostró una investigación periodística sobre el movimiento estudiantil chileno y los grupos radicales que lo conforman, vinculándolos a la explosión de una bomba que se produjo el mismo día en una estación de metro en Santiago. Con base en los Estudios Críticos del Discurso, examinamos los recursos discursivos y semióticos con los que se recontextualizan las acciones y motivaciones estudiantiles, mediante la identificación y descripción de ciertas metáforas multimodales y su función en la deslegitimación de estos colectivos políticos.
\end{abstract}

Palabras clave: Narración, multimodalidad, noticieros, movimiento estudiantil chileno, encapuchados.

\section{Multimodal recontextualization of the actions and motives of the Chilean student movement in a broadcast news report}

\begin{abstract}
In September 2014, Canal 13 broadcasted a journalistic investigation on the Chilean student movement and the radical groups that conform it, linking them to the bomb explosion which had occurred the same day in a subway station in Santiago. We explore the discursive and semiotic resources with which students' actions and motives are recontextualized. In particular, we identify and describe multimodal metaphors and their function in the overall delegitimation of this political collectives, grounded in Critical Discourse Studies.
\end{abstract}

Keywords: Narration, Multimodality, News broadcast, Chilean student movement, Hooded demonstrators.

Recibido: 04/06/17

Aceptado: 04/11/17

Este artículo se deriva de las investigaciones doctorales de las autoras, ambas financiadas por el Programa de Formación de Capital Humano Avanzado de la Comisión Nacional de Investigación Científica y Tecnológica (CONICYT) mediante la Beca de Doctorado en el Extranjero Becas Chile Folio No 72130323 y No 72130132 , respectivamente.

** Chilena. Profesora de Lenguaje y Comunicación, Magíster en Comunicación y Doctora @ en Traducción y Ciencias del Lenguaje, Universidad Pompeu Fabra, España. camila.cardenas.neira@gmail.com

**** Chilena. Magíster en Estudios del Discurso y Doctora (c) en Lingüística, Universidad de Lancaster. Profesora adjunta, Universidad Bernardo O’Higgins, Santiago, Chile. cperez.arredondo@gmail.com 


\section{Introducción}

El 8 de septiembre de 2014 la colocación de una bomba en una estación de metro en Santiago de Chile dio lugar a una extensa cobertura mediática, que tuvo a la figura del estudiante como posible sospechoso. El día del incidente, uno de los principales noticieros de televisión abierta (Teletrece, de Canal 13) presentó un reportaje sobre el movimiento estudiantil y los grupos radicales que lo conforman, titulado "Radiografía a los colectivos estudiantiles". Este informe obtuvo diversas críticas por su emisión oportunista, su falta de evidencia empírica, y las quejas de algunos entrevistados que declararon haber participado bajo engaño (Fernández, 2014).

En este estudio nos proponemos responder cómo este relato periodístico construye a los estudiantes como actores sociales inherentemente agresivos y desviados, y como sujetos sistemáticamente marginalizados y excluidos de la esfera pública (Cárdenas, 2011, 2012, 2014). En particular, examinamos el modo en que el encapuchadose configura como entidad representativa de la juventud movilizada, reparando en los modos como sus acciones y motivos se recontextualizan multimodalmente a partir de determinadas metáforas que organizan las secuencias audiovisuales.

A continuación, aportamos un marco teórico que aborda la cobertura mediática de los eventos de protesta y movilización juvenil. Luego explicamos el diseño metodológico empleado, el que adapta y combina dos modelos provenientes de investigaciones recientes en Semiótica Social y Lingüística Sistémico-Funcional. Después, revisamos algunos resultados prominentes del análisis, los que se ordenan en función de las fases narrativas y sus patrones de significación multimodal recurrentes. Finalmente, exponemos las conclusiones globales de este trabajo.

\section{Marco teórico}

Los movimientos sociales, en general, y los movimientos juveniles, en particular, dependen en buena medida de los medios de comunicación para dar a conocer sus luchas y reivindicaciones. De acuerdo a Cohen \& Young, "los medios tienen que hablar en el mismo idioma -'lenguaje'que la audiencia, no solo en el sentido del vocabulario y la sintaxis, sino en el sentido de ciertas suposiciones comunes acerca de la realidad" ${ }^{11}$

En adelante, las citas textuales en inglés han sido traducidas por las autoras. 
(1973, p. 432). Es así como los medios proveen unas pautas orientadoras que circunscriben las formas de ser y de actuar de los grupos y sirven como importantes instrumentos de dominación (Pardo, 2007, 2009; Van Dijk, 2009). Por consiguiente, los medios ostentan un considerable poder simbólico para intervenir en la visibilización de los movimientos (RoviraSancho, 2013), y determinar hasta qué punto sus actores pueden ser considerados como agentes legítimos o ilegítimos(Gamson\& Meyer, 1999), justificando con ello la adhesión o la represión (Zald, 1999).

Dos planteamientos permiten explicar el vínculo entre medios y movimientos: el paradigma consensual (Cohen, 1973; Cohen \& Young, 1973) y el paradigma de la protesta (Boyle,McCluskey, McLeod \& Stein,2005; McLeod, 2007). A ambos subyace la idea de que los medios constituyen un negocio que fomenta "una comprensión convenientemente engañosa e incompleta del mundo" (Gamson, 1992, p. 5), toda vez que la selectiva representación que proporciona la prensa de los movimientos juega una papel relevante en la formación de opiniones públicas sobre sus manifestaciones y, por lo tanto, en la definición oficial de dichos eventos. En esta dirección, el consenso sirve como tamiz de los conflictos sociales, en cuya base se encuentra "la alianza del poder político con el mediático” (Rovira-Sancho, 2013, p. 39). Cohen \& Young (1973) se refieren a dos modelos que sintetizan estas implicancias, uno manipulativo y otro comercial, los cuales constriñen los procesos de producción informativa priorizando tanto los intereses del mercado como los intereses ideológicos, por lo que su análisis requiere concentrarse tanto en las condicionantes estructurales de la industria informativa como en la construcción e interpretación discursivas.

Estos autores estudian cómo la prensa construye noticias sobre problemas y sujetos contestatarios, mediante la elaboración de textos e imágenes que estigmatizan a un otro peligroso (Artese, 2009) y lo enmarcan dentro de las minorías (Murdock, 1973). Con ello destacan la capacidad de los medios de mostrar lo anormal sobre la base de lo que previamente se ha naturalizado como habitual, de modo que "mientras más desviado sea el grupo, menos legítimamente será retratado" (Shoemaker, 1984, p. 67). Esta contención de la desviación social es explicada por Gamson (1989) a partir de dos factores complementarios: el surgimiento del estado de seguridad nacional y sus mecanismos de vigilancia, junto con el auge de las coberturas centradas en las estrategias de manifestantes y autoridades. De esta forma, las nociones de control y subversión señalan el camino 
retórico que conecta la comunicación de la protesta al rol estereotipador de las elites hegemónicas.

Enfocado en los jóvenes, Cohen $(1972,1973)$ concluye que la prensa configura tres estrategias de representación frecuentes. La exageración consiste en subrayar la gravedad de los asuntos, focalizándose en acontecimientos agresivos, dañinos y destructivos, mientras que la distorsión se expresa en relatos abiertamente criminalizadores. La predicción funciona como una amenaza implícita que anticipa que lo sucedido, inevitablemente, volverá a ocurrir. La simbolización recurre a dos estrategias relacionadas: el uso de determinadas palabras (i.e.encapuchado) que deviene en la creación de cierto estatus (i.e. delincuente), y el énfasis dado a atributos o posesiones particulares (vestimenta, accesorios) que activan emociones y actitudes negativas.

Por su parte, Boyle et al. (2005) proponen que el tratamiento periodístico otorgado a grupos en confrontación responde a un paradigma sistemático que persigue reforzar el statu quo. De esta manera, "la cobertura noticiosa resultante forma un patrón repetido en varios contextos: cuanto más se desvía un grupo de la situación actual con respecto a sus objetivos, tácticas, apariencia, etc., es más probable que los medios de comunicación actúen para marginarlo y despreciarlo" (p. 639).Según McLeod (2007), las principales características de este paradigma son: a) el enmarcado, que opera al seleccionarse ciertos aspectos noticiosos que enfatizan la interpretación causal y la evaluación moral, construyendo marcos típicamente asociados a narrativas delictivas; b) la dependencia de las fuentes oficiales, que busca entregar historias con prestigio en tanto estas "tienden a ser contadas desde la perspectiva de los poderosos, restando importancia a las perspectivas que desafían ese poder" (2007, p. 187); c) la invocación de la opinión pública, que ocurre cuando se da cabida a la ciudadanía para enunciar diferencias entre los manifestantes y la sociedad; d) la deslegitimación, que sucede cuando los medios no explican el contexto de las acciones de protesta, "lo que lleva a la audiencia a percibirlas como inútiles, sin fundamento, e incluso irracionales" (2007, p. 187), y; e) la demonización, que se basa en las coacciones y consecuencias nocivas de las protestas, creando "pánico social en relación con la violencia, los daños a la propiedad, la congestión del tráfico y el gasto de recursos" (2007, p. 187).

En suma, los medios de comunicación son más accesibles a la acción extrainstitucional de los movimientos, y más susceptibles a la guioniza- 
ción y la dramatización de sus acciones (Gamson, 1989). Ambos paradigmas se caracterizan por una orientación a los sucesos, lo que facilita que las explicaciones de los actos y participantes representados mediáticamente coincidan con aquellas provistas por las clases dominantes. Con ello, "la actividad radical aparece como esencialmente efímera, y confinada a un pequeño grupo de extraños, más que como el producto de desigualdades en la distribución de la riqueza y el poder históricamente estructuradas y continuadas" (Murdock, 1973, p. 214).

\section{Metodología}

Este trabajo se circunscribe dentro del paradigma de los Estudios Críticos del Discurso (ECD), según el cual los fenómenos sociales son explorados y desmitificados en términos ideológicos a través del análisis de realizaciones lingüísticas y semióticas situadas en contextos económicos, políticos y culturales concretos (Fairclough, 1995; Titscher, Meyer, Wodak \& Vetter, 2000; Van Leeuwen, 2008; Van Dijk, 2011; Wodak, 2013). Dicho paradigma se caracteriza por privilegiar una aproximación interdisciplinaria y multimetodológica (Weiss \& Wodak, 2003; Fairclough, 2005; Wodak \& Meyer, 2009; Fairclough, Mulderrig \& Wodak, 2011; Van Dijk, 2015), en tanto los métodos propios de los estudios discursivos, así como otros provenientes de las humanidades y las ciencias sociales, pueden ser integrados en la investigación.

El corpus corresponde al reportaje "Radiografía a los colectivos estudiantiles" de 11 minutos y 17 segundos, emitido en la sección "Reporteros" del noticiero nocturno de Canal 13 “Teletrece”, al que accedimos a través de Youtube ${ }^{2}$. La transcripción del video la realizamos con Atlas.ti, y luego la complementamos con los fotogramas correspondientes que organizamos correlativamente. En la matriz, disgregamos los modos verbal, visual y sonoro y reservamos un espacio para ejemplos y anotaciones.

El modelo de análisis que hemos diseñado se fundamenta en desarrollos procedentes de la Semiótica Social y la Lingüística SistémicoFuncional. Por un lado, seguimos las propuestas de representación visual de la metáfora (Feng \& Espindola, 2013a) y de prosodia emocional (Martin \& White, 2005; Feng \& O’Halloran, 2013b; Feng \& Qi, 2014) para identifi-

2 Ver https://www.youtube.com/watch?v=okA54G-Rhck\&t=3s Actualmente el video no está disponible en el sitio web de Canal 13. 
car la estructura narrativa del reportaje y describir cómo se representa a los jóvenes encapuchados en sus fases, experiencias y evaluaciones prominentes. Por otro lado, recurrimos al enfoque de acción social (Van Leeuwen, 2007, 2008) para caracterizar y explicar cómo las distintas modalidades configuran esta narrativa a partir de las deslegitimaciones asociadas al movimiento estudiantil en los discursos de los medios de comunicación tradicionales (Pérez, 2012, 2016). El análisis se ejecuta en dos niveles tal como detallamos a continuación.

\subsection{Macro-análisis}

En el nivel macro identificamos y describimos la estructura narrativa del reportaje de acuerdo a las principales metáforas presentes en las secuencias audiovisuales. Para esto trabajamos con base en las metafunciones del lenguaje (Halliday \& Matthiessen, 2014) y sus opciones de construcción de significados: textual (s-tex), ideacional (s-ide) e interpersonal (s-int), con el propósito de abordar, respectivamente:1) la organización del relato: ¿cómo se ordenan los eventos en los que se involucran los jóvenes a partir de criterios temporales y/o causales específicos?; 2) la progresión de los protagonistas y sus objetivos: ¿cómo se representa a los jóvenes y sus acciones en el reportaje?, y; 3) el acompañamiento de la audiencia: ¿cómo se inscriben y/o evocan evaluaciones vinculadas a los jóvenes, sus rasgos y relaciones?

Figura 1. Estructura del análisis narrativo. Fuente: elaboración propia.

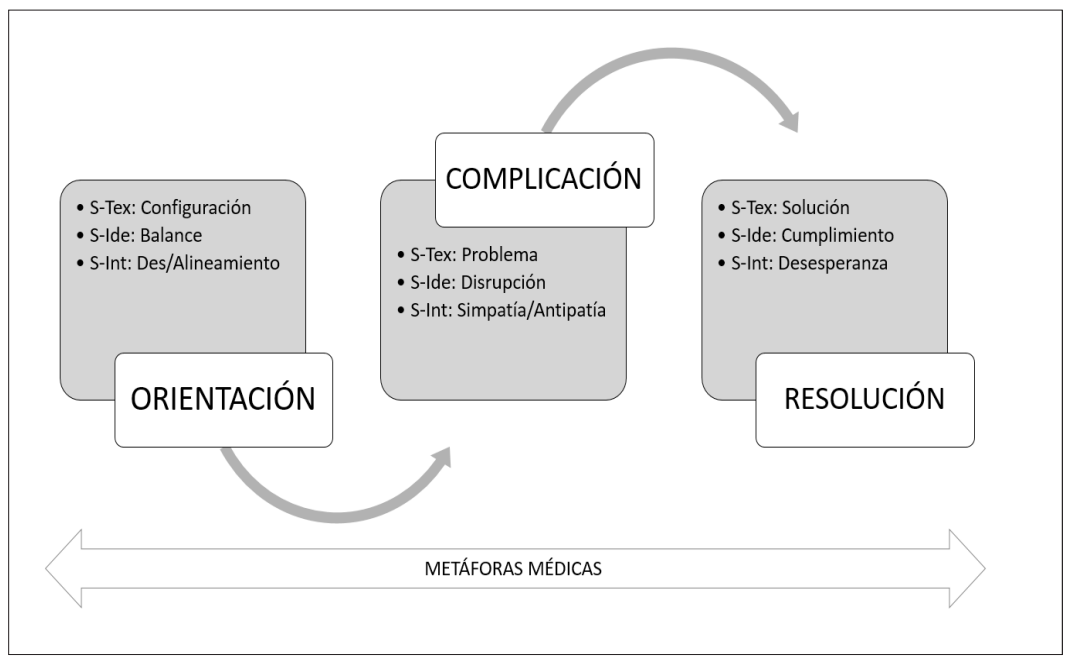


Como muestra la Figura 1, la narración se sustenta en determinadas metáforas médicas desprendidas de la noción de radiografía, las cuales dan coherencia simbólica a tres secuencias fundamentales: orientación, complicación y resolución(Cfr. Labov \& Waletzky, 1967). A su vez, cada secuencia incluye, según Feng \& Qi (2014, p. 353), etapas (configuración, problema, solución), estados de experiencia (balance, disrupción, cumplimiento) y estados emocionales (alineamiento o desalineamiento, simpatía o antipatía, desesperanza) que les son particulares, cuyas estrategias de representación buscamos dilucidar y articular.

\subsection{Micro-análisis}

En el nivel micro caracterizamos y explicamos el funcionamiento de cada modalidad semiótica. Puntualmente, ponemos énfasis en la representación multimodal del encapuchado en términos de: 1) las estrategias referenciales empleadas:¿cómo se les identifica?; 2) las estrategias predicacionales asociadas: ¿cuáles acciones se les atribuyen?; 3) las estrategias de recontextualización seleccionadas: ¿cómo actores y acciones son trasladados(as) desde el contexto social al contexto informativo recreado por el reportaje?, y; 4) las estrategias de (des)legitimación privilegiadas: ¿cómo actores y acciones son o no validados(as) en la historia formulada por el relato periodístico? Véase una esquematización en la Figura 2.

Figura 2. Estructura del análisis multimodal. Fuente: elaboración propia.

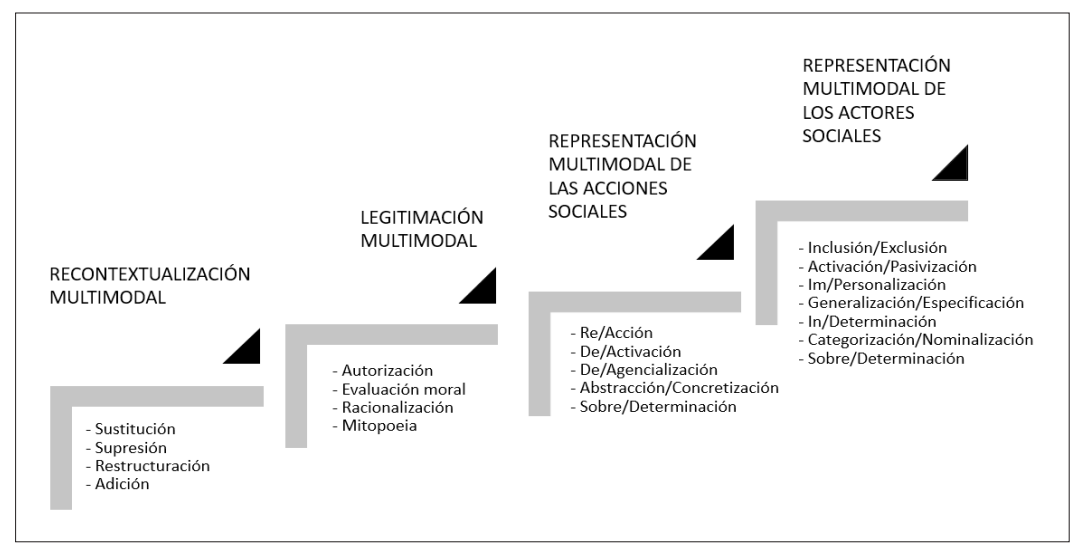

Entendemos que las relaciones intersemióticas se fundan en un principio de inconmensurabilidad según el cual "el significado concreto en uso 
depende de la forma en que su potencial (...) es transversalmente contextualizado con respecto a las características del entorno en el que aparece el signo" (Lemke, 2005, p. 17). Esto supone, por ejemplo, que incluso en un texto que parece concordante con la imagen, cada modalidad puede interpretarse como afirmando o socavando el sentido de la otra (K. L. E, O'Halloran \& Judd, 2011). Por lo tanto, si bien las estrategias mencionadas se realizan simultáneamente, debemos establecer si los enunciados verbales, las imágenes y los sonidos aportan significados congruentes o incongruentes, esto es, si resultan complementarios o divergentes entre sí (Lim, 2004).

\section{Resultados}

\subsection{Secuencia de orientación}

\subsubsection{Macro-análisis}

En la secuencia de orientación (S-ORI) se busca constatar un estado de cosas desequilibrado y peligroso como si se tratara de una situación de conflictividad permanente (s-tex: configuración). Para ello se lleva a cabo una contextualización polifónica [COMPROMISO: Heteroglosia: Expansión dialógica: Atribución: Inserción], a partir de las intervenciones de distintas voces (autoridad experta, autoridad policial, dirigentes estudiantiles, reportero) que introducen superficial y parcialmente a los protagonistas, sus acciones y objetivos con alto nivel de habitualidad y radicalización, aunque en apariencia se proponga un relato periodístico ponderado.

Esta fase se aboca a la representación de un estado de amenaza social como experiencia naturalizada ( $s$-ide: balance), mediante la completación de significados en el modo verbal (e.g. voz en off del reportero: "No ha habido una sola semana desde agosto a la fecha [FUERZA alta: Cuantificación: Extensión: Alcance: Tiempo] en la que grupos de encapuchados no se hayan hecho notar hasta convertirlo en un hecho cotidiano" [- JUICIO: Normalidad (evocada)], [FUERZA alta: Cuantificación: Frecuencia],[COMPROMISO: Monoglosia]), visual (e.g. secuencias de imágenes de enfrentamientos entre encapuchados y policías, de las calles ocupadas con destrozos, fuego y gases lacrimógenos, etc.), y sonoro (e.g. música de suspenso y audio incidental -disparos, vidrios rompiéndose, gritos, etc.-), recursos que a la larga propenden a un efecto de recontextualización negativa. 
Adicionalmente, se plantean interacciones a partir de la distinción general entre endogrupo (la sociedad) y exogrupo (los antisociales) (s-int: des/ alineamiento), con miras a promover el distanciamiento de la audiencia en relación con individuos, grupos y actos de violencia, y, consecuentemente, suscitar más cercanía con quienes padecen sus efectos (los ciudadanos) y buscan reestablecer el orden trastocado (la policía). Se espera que esta división module en adelante el conjunto de valoraciones inscritas y evocadas que se instancian en el transcurso del reportaje. Concretamente, es el modo visual el que mejor propone significados en esta dirección, en tanto se intercalan tomas que formulan evaluaciones negativas en torno a: i) las acciones de los encapuchados (e.g. [- JUICIO: Sanción Social: Integridad]); ii) las pugnas que se generan en el espacio callejero (e.g. [- APRECIACIÓN: $\uparrow \downarrow$ Poder],[- APRECIACIÓN: $\uparrow$ Conflictividad social]), y; evaluaciones positivas sobre: iii) las acciones de carabineros y fuerzas especiales (e.g. [+ JUICIO: Estima Social: Capacidad/Tenacidad]).

Estas y otras realizaciones ayudan a construir tres metáforas médicas que otorgan coherencia simbólica a S-ORI: disfunción, diagnóstico, síntomas. Todas ellas dan cuenta de la detección de un comportamiento irregular dentro de un cuerpo mayor (la sociedad). Aunque el foco de S-ORI está puesto en modelar estos actos anómalos y a sus responsables anónimos, la participación estudiantil puede recuperarse de las declaraciones de los dirigentes entrevistados y de la repetición de ciertas imágenes que registran marchas estudiantiles. Estas metáforas no solo normalizan la acción presuntamente usual de encapuchados y el modo como esta afecta la seguridad social, sino que además estabilizan una asociación fundante entre juventud y amenaza, cuyo examen -radiografía- se presenta para ser inspeccionado por los televidentes.

\subsubsection{Micro-análisis}

La colectivización de las acciones fundamenta la representación de una masa descontrolada, asociación facilitada por la indiferenciación de esta corriente transgresora que, aunque minoritaria y externa al movimiento estudiantil en los hechos, se insinúa formando parte de sus dominios. Esta representación también se sostiene en las declaraciones de distintos estudiantes que definen a estos grupos desde la postura de un nosotros inclusivo (activación, agrupación), pese a que sus intervenciones buscan proponer, desde otra perspectiva, una narrativa de la injusticia social (e.g. entrevista a Juan Vega, Colectivo "Vamos": "Nosotros como 
colectivo más que todo entendemos [HETEROGLOSIA: Expansión dialógica: Consideración] que la violencia nace de... de una rabia generada [- AFECTO ENCUBIERTO: Insatisfacción] por este sistema que violenta [- APRECIACIÓN: Integridad (evocada)] a las personas día a día").

Las secuencias visuales de ataques y sus efectos en la vía pública subsumen la movilización juvenil en un vandalismo extendido. Varias de estas imágenes favorecen la relación entre encapuchados y estudiantes mediante la referencia a lugares de actuación comunes, como sucede al incorporar tomas de las fachadas de establecimientos educacionales icónicos (e.g. Liceo de Aplicación, Universidad de Chile). A esto se suma el uso indistinto y reiterado de denominaciones (e.g. encapuchados, anarquistas, radicales) por parte del reportero, con las cuales se va conformando un campo semántico de naturaleza antisistémica (generalización, nominalización).

En cuanto a la adjudicación de motivos, S-ORI contiene una poderosa estrategia de deslegitimación: un ataque al país, al orden civil y al statu $q u o$. Esto es retratado en una secuencia editada, en donde primero se muestra a un encapuchado lanzando un artefacto incendiario y luego se enfoca una bandera chilena en llamas (imágenes min. 00.53-00.57). Metonímicamente, el objeto alude al país contra el que estos sujetos atentan (PROPÓSITO: (IR) encapuchado lanza una bomba molotov para destruir la bandera/nación). La secuencia se observa mientras se oye una declaración de un oficial de carabineros, quien explica que "el fin último de estos individuos es causar el mayor daño posible [FUERZA alta: Cuantificación]; [- JUICIO: Sanción Social: Integridad (inscrita)] a lo que es vehículos policiales y también al personal".

En términos generales, las relaciones intersemióticas resultan incongruentes o divergentes. Verbalmente, las acciones de los estudiantes son representadas como reacciones legítimas, mientras que visualmente estas son homogeneizadas, llevadas permanentemente a un segundo plano, siendo las acciones de la policía las más prominentes, montaje que favorece la atribución implícita de intencionalidad.

\subsection{Secuencia de complicación}

\subsubsection{Macro-análisis}

La secuencia de complicación (S-COM) se subdivide en seis etapas a partir de las cuales se realiza un análisis exhaustivo de los grupos investigados y sus patrones de identificación (s-tex: problema): 1) declaración 
de vínculos explícitos con el movimiento estudiantil; 2) definición de modus operandi; 3) estimación de repercusiones e impactos; 4) indagación de colectivos y casos concretos; 5) descripción de recursos y estrategias de visibilización y coordinación, y; 6) revisión de procesos y sentencias judiciales recientes. Estas facilitan la progresión del relato periodístico y la construcción de causalidad entre eventos que no necesariamente evidencian una conexión lógica, como ocurre, por ejemplo, con 5 y 6 . Dicha organización estaría respondiendo, como veremos luego, a la estructura de una historia cautelar, que advierte lo que sucede cuando determinados actores no se ajustan a las normas establecidas.

En esta línea, se torna patente la finalidad de relacionar directamente a los participantes y sus acciones desviadas con el movimiento estudiantil y sus mecanismos de protesta, implicando la indiferenciación de sus miembros, objetivos y luchas (s-ide: disrupción). Esto se consigue mediante cuatro estrategias de representación: 1) rutinización de los actos de violencia (e.g. voz en off del reportero: "Los desórdenes se dan entre el medio día y las cuatro de la tarde, nunca los viernes por temor a quedar deteni$\underline{\text { dos }}$ [- AFECTO ENCUBIERTO (irrealis): Miedo] todo el fin de semana"); 2) conformación de células profesionalizadas (e.g. voz en off del reportero: "Un grupo de encapuchados comienza los disturbios. Se mueven y esconden por rincones que conocen de memoria" [- JUICIO: Sanción Social: Integridad (evocado)]); 3) cuantificación de daños a personal e infraestructura policial (e.g. imágenes min. 03.50-03.54: zoom in progresivo a un carro lanza-gases incendiándose, se aprecia la silueta de un encapuchado en primer plano[- APRECIACIÓN: $\uparrow \downarrow$ Poder] $\rightarrow$ gatillador: disputa policías/ antisociales), y; 4) judicialización y condena pública(e.g. imágenes min. 06.49-07.02: toma de un fiscal leyendo una sentencia [+ JUICIO: Estima Social: Capacidad] $\rightarrow$ gatillador: acción de jueces).

Como se desprende de estos ejemplos, esta secuencia busca reforzar en la audiencia sentimientos de aprobación o reprobación en torno a los actores sociales evaluados, sus atributos y fines recurrentes (s-int: simpatía/antipatía). Con ello no solo se fijan las características y los propósitos presuntamente innatos de estos grupos, sino que se exacerban actitudes positivas y negativas que erigen una división moral y ética entre individuos (encapuchados, radicales, anarquistas v/s policías, ciudadanos comunes) e instituciones (fuerzas de orden, poder judicial).

Estas y otras realizaciones ayudan a construir tres metáforas médicas que dan coherencia simbólica a S-COM: invasión, contagio, pade- 
cimiento. Todas ellas dan cuenta de la irrupción de un cuerpo extraño al interior de un cuerpo mayor (el movimiento estudiantil). De este modo, se verifica la propagación de los comportamientos beligerantes, subversivos y destructivos propios de los encapuchados hacia los colectivos y las organizaciones juveniles, cuya acción resulta no solo frecuentemente generalizada, sino también objetivada como intrínsecamente maliciosa.

\subsubsection{Micro-análisis}

Destacamos dos episodios que contribuyen a la construcción del encapuchado como representante de la juventud movilizada. El primero corresponde a la incorporación de un vídeo amateur, en donde (supuestamente) estudiantes graban el mensaje que carabineros dirige a un grupo de encapuchados que causa desmanes en las cercanías de un campus universitario (PROPÓSITO: (IR) corren tras un carro lanza-aguas para quemarlo). Esta conexión es realizada verbalmente por un policía cuando identifica a las víctimas de los ataques como "sus mismos compañeros" (min. 05.02-05.14). Mientras este interviene se escuchan risas y gritos de burla, lo que facilita la interpretación de estas acciones como inherentes a una juventud irreverente e irrespetuosa de la autoridad.

El segundo episodio alude a la inclusión de evidencia visual sobre la acción delictiva de grupos anarquistas y su castigo subsecuente (judicialización), lo que ayuda a configurar una narrativa criminal que es complementada con texto oral y escrito. Se enfatiza cómo estos grupos se organizan digitalmente y utilizan distintas páginas web y redes sociales para distribuir propaganda, fortaleciendo la metáfora médica de una infección que se esparce. Asimismo, es la primera vez en la cual los encapuchados son individualizados para recalcar su ligazón con el mundo estudiantil (voz en off del reportero: "Alejandro Quiroz, sentenciado a 3 años y 1 día [...], es profesor"). Esta etapa responde a una mitopoeia clásica en donde el bien triunfa sobre el mal, representación que se cristaliza con la inserción de imágenes del operativo policial (allanamiento y detención) y de la formalización correspondiente. Las tomas son realizadas con visión nocturna y el uso simultáneo de música de tensión -comúnmente empleada en programas de persecución policial (docurealities)-, exacerbando consigo emociones negativas vinculadas con el temor y la inseguridad. 
En S-COM también se aprecian relaciones intersemióticas incongruentes o divergentes. Verbalmente, los manifestantes encapuchados son representados como actores orientados a objetivos (i.e. ir a la universidad para atacar a la policía), aunque en el modo visual los encapuchados son mostrados realizando acciones no transactivas (meta ausente). De acuerdo a la estructura narrativa, es posible sugerir que la audiencia pudo haber sido predispuesta a interpretar causalmente esta secuencia, donde los hechos de agresión y vulneración llegan a su clímax.

\subsection{Secuencia de resolución}

\subsubsection{Macro-análisis}

La secuencia de resolución (S-RES) busca demostrar el enquistamiento de agrupaciones violentistas al interior del movimiento estudiantil ( $s$-tex: solución), a través de cuatro etapas generales: conformación, distinción, ejemplificación y evolución. A diferencia de S-COM, estas parecen responder a una organización más lógica y articulada, que permite derivar inferencias sobre su composición, fundamentos y trayectoria histórica. Un aspecto crítico en este sentido tiene que ver con la repetición de las denominaciones "grupos" y "colectivos", dado que ambas son empleadas indistintamente para aludir a jóvenes orientados a la formación de una alternativa política, por un lado, y a la incitación de la insurrección social, por el otro, homologándose como mutuamente constitutivas del movimiento estudiantil.

El reportaje concluye al corroborar esta relación estructural, concretándose la representación del movimiento como fuente de radicalización juvenil, cuyo carácter sedicioso resultaría indisociable de sus repertorios de protesta y figuración pública ( $s$-ide: cumplimiento).Las formas en que los estudiantes se rebelan ante la autoridad institucional y policial son, según el relato periodístico: 1) desmarcarse de las juventudes partidistas tradicionales; 2) escalar en las jerarquías de poder; 3) aumentar la representatividad en las bases estudiantiles, y; 4) conquistar una "tercera vía" (¿no bipartidista?). En términos semióticos, esto se consigue explicando, por una parte, la emergencia de colectivos políticos legitimados dentro del mundo estudiantil, y exponiendo, por otra parte, numerosas expresiones de vandalismo, desobediencia e insubordinación juvenil.

Con base en esta experiencia se pretende promover en los espectadores la adopción de un estado anímico desmoralizante y desalentador respecto 
a las consecuencias negativas que supone desvelar el vínculo entre acción política juvenil y acción juvenil insurgente. Por lo tanto, la asociación entre juventud, amenaza y desviación ya circunscrita en las secuencias previas, se representa aquí como ineludible, y sus secuelas, como esencialmente perjudiciales (s-int: desesperanza). Para lograrlo se emplea una estrategia de montaje audiovisual que consiste en alternar juicios positivos sobre el movimiento estudiantil, su nivel de cohesión y articulación para organizarse masivamente (e.g. [+ JUICIO: Estima Social: Capacidad (evocado)], [+ APRECIACIÓN: Reacción: Impacto (inscrito)]),procedentes principalmente de testimonios de dirigentes y expertos e imágenes de marchas multitudinarias y festivas (e.g. [+ AFECTO: Felicidad]), con evaluaciones negativas realizadas tanto verbal (e.g. voz en off del reportero: “Si bien la mayoría de los radicales [FUERZA: Cuantificación] proviene de colectivos estudiantiles, hay otros grupos que quieren escapar de la estigmatización violentista" [- JUICIO: Sanción Social: Integridad (evocado)]) como visualmente (e.g. imágenes min.10.52-11.02: una cámara de seguridad capta a una aglomeración de manifestantes dispersándose por el efecto del carro lanza-aguas [- APRECIACIÓN: $\uparrow$ Conflictividad social] $\rightarrow$ gatillador: fuerzas en disputa por el espacio público).

Estas y otras realizaciones ayudan a construir tres metáforas médicas que dan coherencia simbólica a S-RES: colapso, metástasis, propagación. Todas ellas dan cuenta de la diseminación de un cuerpo extraño dentro de un cuerpo mayor (el movimiento estudiantil primero, y la sociedad en su conjunto después). Así, se implica que las manifestaciones de violencia propias de los encapuchados son concomitantes a los modos de agrupación alternativos de los jóvenes, con lo que termina por confirmarse la premisa del reportaje.

\subsubsection{Micro-análisis}

Esta secuencia es introducida con una sucesión rápida de imágenes en las que la acción no transactiva de encapuchados y carabineros se configura continuamente bajo un esquema de confrontación. A partir de este trabajo de enmarcado, se procede a la identificación de colectivos en tres colegios emblemáticos de Santiago, a lo que se suman las intervenciones de tres dirigentes estudiantiles. La auto-representación juvenil parte del supuesto de que sus acciones tienden a ser consideradas inherentemente violentas por las autoridades (e.g. entrevista a Juan Vega, Colectivo "Vamos": “[...] tú no le podís decir a un loco que ha vivido violentado 
toda su vida [- JUICIO: Sanción Social: Integridad (evocado); FUERZA alta: Cuantificación: Extensión: Alcance: Tiempo], cachay, puta suelta esa piedra, cachay, y levanta las manos y deja que los pacos te peguen"), culminando la resignificación de estas prácticas desde una perspectiva contraria, al representar a los jóvenes manifestantes reaccionando ante la violencia ejercida por el Estado:

Figura 3. Deslegitimación de la mitopoeia presentada por Juan Vega, Colectivo "Vamos" (min. 10.17-10.40).
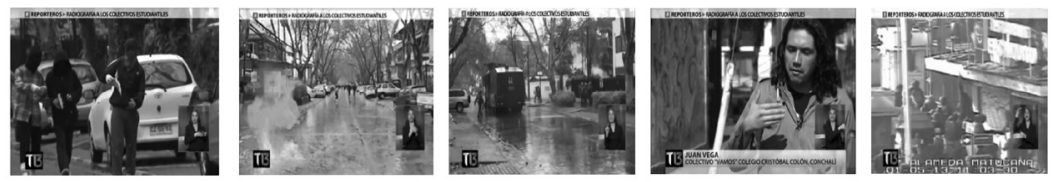

Tanto el registro informal utilizado (intensificadores como cachay; interjecciones como puta; o nominalizaciones como loco, en vez de persona, joven,etc., o pacos, en lugar de policías), como el muro con grafitis que se aprecia en segundo plano sirven como estrategias de deslegitimación de los colectivos estudiantiles y de los sectores periféricos de donde presuntamente provienen. El énfasis dado al nivel socioeconómico de estos alumnos sirve para normalizar ciertas características indisociables de los encapuchados, a pesar de que Juan Vega intenta hacer una reversión de la mitopoeia tradicional cuando interpreta los ataques de los encapuchados como un resultado de la violencia material y simbólica que estos sujetos padecen (e.g. David v/s Goliat). Esta representación se consolida con una secuencia de tomas de cámaras de seguridad en donde se observa a una turba de encapuchados destruyendo la cortina metálica de un local comercial, en lo que pareciera ser un intento de saqueo, facilitando la asociación entre encapuchados e individuos marginalizados (colapso, infección).

Finalmente, el reportaje reafirma en el modo visual la existencia de un escenario devastador (e.g. imágenes min. 09.50-10.12: grupos de encapuchados lanzando objetos (piedras, palos, molotov) a las afueras de un parque y un edificio [- JUICIO: Sanción Social: Integridad $\rightarrow$ gatillador: acción de encapuchados), mientras que en el modo verbal se subraya el rol influyente adquirido por los grupos radicales dentro del movimiento estudiantil (e.g. voz en off del reportero: "Colectivos que buscan una tercera vía, una que hoy los posiciona como una voz de fuerza [+ JUICIO: Estima Social: Capacidad (evocado)] dentro del movimiento estudiantil"). A medida que este texto es narrado, por pri- 
mera vez se incluye una secuencia rápida de manifestaciones pacíficas protagonizadas en su mayoría por secundarios. La gran cantidad de estudiantes, el detalle de sus uniformes, y la aceleración de las imágenes facilitan la asimilación y la colectivización de los jóvenes. De esta forma, el trabajo de montaje y edición no solo otorga saliencia visual al movimiento estudiantil en los segundos finales del reportaje, sino que también refuerza la representación de que la intrusión violentista es una amenaza que crece peligrosamente al amparo de las juventudes movilizadas.

\section{Conclusiones}

Las metáforas permiten enmarcar ideológicamente las construcciones con las cuales entendemos el mundo, determinando la legitimación de actores y acciones y cómo reaccionamos emocionalmente a ciertas situaciones (Charteris-Black, 2005; Hart, 2017). En este sentido, los resultados de este estudio muestran que las metáforas médicas facilitan la vinculación de los encapuchados con los colectivos estudiantiles en tanto organismos cuya interacción afecta a un cuerpo mayor como es la sociedad. Por tanto, las etapas narrativas simbolizan los estados de detección, irrupción y diseminación de la enfermedad que atacaría al país bajo la metáfora dominante ESTUDIANTE ENCAPUCHADO es CÁNCER. Esta comparación se consigue mediante la articulación de significados ideacionales, interpersonales y textuales que tornan inteligible la identificación de los jóvenes y sus objetivos antisociales, los sentimientos de inseguridad, temor y reprobación que se derivan de estos sujetos y sus comportamientos típicos, y las repercusiones perjudiciales que suscita esta dependencia, respectivamente.

Esta narrativa se funda en la representación negativa de la juventud y de sus formas de actuación grupal, a partir del funcionamiento de tres modos semióticos: textual, visual y sonoro. En el modo verbal, los jóvenes son impersonalizados y colectivizados a través del uso indistinto de categorizaciones tales como encapuchados, capuchas, anarquistas y radicales. Asimismo, nominalizaciones como ataques, protestas y manifestaciones homogenizan y tipifican las acciones involucradas con base en sus niveles de habitualidad y radicalidad. En el modo visual, las secuencias reiteradas de disturbios y enfrentamientos en el espacio callejero potencian en la audiencia la incorporación de preconcepciones y prejuicios en torno al 
significado social del encapuchado, sus conductas y propósitos disruptivos y subversivos. En el modo sonoro, el uso de sirenas, explosiones y música de tensión que son características de los programas policiales consolida una narrativa espectacular y criminalizante, según la cual se estabiliza la relación entre juventud, amenaza y desviación social. Así, la motivación de estos actores se interpreta como intencionalmente maliciosa, orientada a causar destrozos en la esfera pública y privada y colapsar la sociedad. En suma, el relato periodístico no se centra meramente en el movimiento y los colectivos que lo conforman, sino que además estereotipa las formas de organización y acción política juvenil asentadas durante sus recientes ciclos de protesta (2006-2016).

\section{Referencias bibliográficas}

Artese, M. (2009). Criminalización de la protesta en Argentina. Una construcción de lo delictivo más allá de la esfera jurídica. América Latina Hoy, (52), 149-169.

Boyle, M., McCluskey, M., McLeod, D. \& Stein, S. (2005). Newspaper and protest: An examination of protest coverage from 1960-1999. Journalism \& Mass Communication Quarterly, 82(3), 638-653.

Cárdenas, C. (2011). (In)visibilización juvenil: Acerca de las posibilidades de las y los jóvenes en la historia reciente del país. Última Década, 19(35), 11-31.

(2012). ¿Dónde debe emplazar su ojo la historia? (In)visibilización de las y los jóvenes en discursos disciplinares que recuperan el pasado reciente chileno (1970-1990). Discurso \& Sociedad, 6(2), 283-313.

(2014). Jóvenes e (in)visibilización histórica: Modos de representación ideológica de la juventud chilena en el pasado reciente (1970-1990). Signos, 47(85), 217-244.

Charteris-Black, J. (2005). Politicians and rhetoric: The persuasive power of metaphor. Houndmills: Palgrave Macmillan.

Cohen, S. (1972). Folk devils and moral panics: The creation of the Mods and Rockers. London: Routledge.

(1973). Mods and Rockers: The inventory as manufactured news. In

S. Cohen \& J. Young (Eds.), The manufacture of news. Deviance social problems \& mass media (pp. 263-279). London: Constable. 
Cohen, S. \& Young, J. (1973). Effects and consequences. In S. Cohen \& J. Young (Eds.), The manufacture of news. Deviance social problems \& mass media (pp. 425-440). London: Constable.

Fairclough, N. (1995). Critical discourse analysis: The critical study of language. London-New York: Longman. . (2005). Critical discourse analysis in transdisciplinary research. En R. Wodak \& P. Chilton (Eds.), A new agenda in (critical) discourse analysis: Theory, methodology and interdisciplinarity (pp. 53-70). Amsterdam-Philadelphia: John Benjamins.

Fairclough, N., Mulderrig, J. \& Wodak, R. (2011). Critical discourse analysis. En T. Van Dijk (Ed.), Discourse studies. A multidisciplinary introduction ( $2^{\text {nd }} E d$.) (pp. 357-378). London: Sage.

Feng, D. \& Espindola, E. (2013). Integrating systemic functional and cognitive approaches to multimodal discourse analysis. Ilha do Desterro, (64), 85-110.

Feng, D. \& O'Halloran, K. L. (2013a). The visual representation of metaphor. Review of Cognitive Linguistics, 11(2), 320-335. - (2013b). The multimodal representation of emotion in film: Integrating cognitive and semiotic approaches. Semiotica, (197), 79-100.

Feng, D. \& Qi, Y. (2014). Emotion prosody and viewer engagement in film narrative: A social semiotic approach. Narrative Inquiry, 24(2), 347-367.

Fernández, B. (2014). C13 suma dieciocho denuncias por reportaje que vincula bombazo al movimiento estudiantil [Noticia]. El Mostrador. Consultado el 12 de septiembre de 2014 en http://www.elmostrador.cl/noticias/pais/2014/o9/10/c13-suma-dieciocho-denunciaspor-reportaje-que-vincula-bombazo-al-movimiento-estudiantil/

Gamson, W. \& Meyer, D. (1999). Marcos interpretativos de la oportunidad política. En D. McAdam, J. McCarthy\&M. Zald (Eds.), Movimientos sociales: Perspectivas comparadas (pp. 389-412). Madrid: Itsmo.

Gamson, W. (1989). The strategy of social protest. Sociological Forum, 4(3), 455-467.

(1992). Talking politics. Cambridge: Cambridge University Press. 
Halliday, M. A. K. \& Matthiessen, C. (2014). Halliday's Introduction to Functional Grammar ( $4^{\text {th }}$ Ed.). London-New York: Routledge.

Hart, C. (2017). An experimental approach to the legitimating functions of fire metaphors in discourse on protest. Discourse and Text Research Group. Lancaster: Lancaster University.

K. L. E., M., O’Halloran, K. \& Judd, K. (2011). Working at cross-purposes: Multiple producers and text-image relations. Text \& Talk, 31(5), 579-600.

Labov, W.\& Waletsky, J. (1967). Narrative analysis: Oral versions of personal experience. En J. Helm (Ed.), Essays on the verbal and visual arts (pp. 12-44). Seattle: University of Washington Press.

Lemke, Jay. (2005). Critical analysis across media: Games, franchises, and the new cultural order. En M. Labarta Postigo (Ed.), Approaches to critical discourse analysis (pp. 1-21). Valencia: Universidad de Valencia.

Lim, V. (2004). Developing an integrative multi-semiotic model. In K. O'Halloran (Ed.), Multimodal discourse analysis: Systemic functional perspectives (pp. 220-246). London: Continuum.

Martin, J. \& White, P. (2005). The language of evaluation. Appraisal in English. Hampshire-New York: Palgrave Macmillan.

McLeod, D. (2007). News coverage and social protest: How the media's protest paradigm exacerbates social conflict. Journal of Dispute Resolution, (1), 185-194.

Murdock, G. (1973). Political deviance: The press presentation of a militant mass demonstration. En S. Cohen \&J. Young (Eds.), The manufacture of news. Deviance social problems \& mass media (pp. 206-225). London: Constable.

Pardo, N. (2007). Discurso, impunidad y prensa. Bogotá: Universidad Nacional de Colombia.

. (2009). Los bordes en la significación discursiva y la mediación mediatizada. Revista Comunicación y Ciudadanía, (1), 54-73.

Pérez, C. (2012). The Chilean student movement and the media: A comparative analysis on the linguistic representation of the 04 August 2011 manifestation in right-wing and left-wing newspapers. Logos, 22(2), 4-26. 
(2016). La representación visual del movimiento estudiantil chileno en la prensa establecida y alternativa nacional: Un análisis multimodal. Revista Austral de Ciencias Sociales, (30), 5-26.

Rovira-Sancho, G. (2013). Activismo mediático y criminalización de la protesta: Medios y movimientos sociales en México. Convergencia, $20(61), 35-60$.

Shoemaker, P. (1984). Media treatment of deviant political groups. Journalism Quarterly, 61(1), 66-82.

Titscher, S., Meyer, M., Wodak, R. \& Vetter, E. (2000). Methods of text and discourse analysis. London: Sage.

Van Dijk, T. (2009). Discurso y poder. Barcelona: Gedisa.

(2011). Introduction: The study of discourse. En T. Van Dijk (Ed.), Discourse studies. A multidisciplinary introduction ( $2^{n d} \mathrm{Ed}$.) (pp. 1-34). London: Sage.

(2015). Critical discourse analysis. In D. Tannen, H. Hamilton \&D. Schiffrin (Eds.), The handbook of discourse analysis $\left(2^{\text {nd }}\right.$ Ed.) (pp. 466-485). Chichester: John Wiley \& Sons.

Van Leeuwen, T. (2007). Legitimation in discourse and communication. Discourse \& Communication, 1(1), 91-112.

_. (2008). Discourse and practice: New tools for critical discourse analysis. Oxford: Oxford University Press.

Weiss, G. \& Wodak, R. (2003). Introduction: Theory, interdisciplinarity and critical discourse analysis. En G. Weiss \&R. Wodak (Eds.), Critical discourse analysis: Theory and interdisciplinarity (pp. 1-32). Hampshire-New York: Palgrave Macmillan.

Wodak, R. \& Meyer, M. (2009). Methods of critical discourse analysis. London: Sage.

Wodak, R. (2013). Critical discourse analysis - Challenges and perspectives. En R. Wodak (Ed.), Critical discourse analysis (Vol. I) (pp. xix-xli). London: Sage.

Zald, M. (1999). Cultura, ideología y creación de marcos estratégicos. En D. McAdam, J. McCarthy \& M. Zald (Eds.), Movimientos sociales: Perspectivas comparadas (pp. 369-388). Madrid: Itsmo. 